\title{
Relationship between age and Breast Self-Examination among women in Nigeria
}

\author{
Abdurrahman Muhammad Sani ${ }^{1}$, RN, RM, BNSC, RPHN, FWACN, NIM, MSCN \\ Dr. Florence $\mathrm{Naab}^{2}$, SRN, RM, BA, MPhil, PhD \\ ${ }^{I}$ Department of Nursing Sciences, College of Health Science, Usmanu Danfodiyo University Sokoto, Nigeria. \\ ${ }^{2}$ School of Nursing, University of Ghana, Legon, Ghana.
}

\begin{abstract}
Breast cancer has now become the most commonly diagnosed cancer among women in several SubSaharan African countries, a shift from previous decades in which cervical cancer was the most commonly diagnosed cancer in many of these countries. One potentially important strategy in reducing breast cancer mortality is breast cancer screening to achieve earlier detection of cancer through Breast Self-Examination. So, creating awareness which is a very important tool entails better screening of breast cancer especially in middle and low income countries. This study examined the relationship between age and Breast Self-Examination among women in Sokoto, Nigeria. Cross sectional design was used to recruit 400 participants using multistage sampling technique. Findings of this study show that majority of the respondents had average knowledge of Breast Self-Examination but only few practiced Breast Self-Examination regularly. Moreover, a significant positive relationship was found between age of the respondents and the knowledge and practice of Breast SelfExamination. There is the need for nurses to teach women the correct procedure for Breast Self-Examination and the importance of regular Breast Self-Examination practice.
\end{abstract}

Keywords: Breast Self-Examination, Relationship, Age, Nigeria

\section{Introduction}

Breast self-examination (BSE) is a non-invasive adjuvant screening method for detection of early breast cancer. And is a useful measure when mammography screening is not available in the rural and poor urban areas ${ }^{1}$. There is evidence that women who correctly practice BSE monthly are more likely to detect lump at the early stages of its development and early diagnosis has been reported to produce good prognosis ${ }^{1}$. Breast Self-Examination refers to a woman being aware of the normal look and feel of her breasts and looking for changes in size or shape of the breasts, the presence of lumps, skin dimpling, redness, discharge or unusual pains $^{2,3,4}$.

For younger women, BSE is often the only method that is available to them to detect abnormal changes at an early stage due to the inaccuracy and ineffectiveness of other screening tests ${ }^{5,6}$, and due to their greater breast tissue density ${ }^{7,8}$. Regular BSE is a cost-effective, convenient, private and simple method that does not require specific equipment ${ }^{\text {, } 10}$. Despite these benefits, only $18 \%-36 \%$ of women perform BSE ${ }^{11}$.

There is a significant difference in the perception of the risk and benefit of BSE procedure between different age groups ${ }^{12}$. Older women who have a higher perception of risk of getting breast cancer are more likely to undertake regular BSE. Whereas, there is no correlation found between younger women and perceive risk of breast cancer and association with $\mathrm{BSE}^{12,13}$. This could be because it is known by women that breast cancer risk increases with age and young women do not feel that they are at risk until they reach an older age. Therefore, they see no need to undertake regular BSE practice.

Whilst mammography is not an accurate screening tool for young women, it is important that young women are targeted for educational programmes that provide information about what is normal and abnormal and increase their breast awareness ${ }^{14}$ as well as exploring their current knowledge ${ }^{15}$. There is a significant lack of information and research that addresses young women's knowledge and perceived barriers to breast cancer information and BSE practice. Although some studies show that, young women have a high level of knowledge of BSE but they do not practice BSE ${ }^{12}$. Alharbi, Alshammari, Almutari, Makboul and El-Shazly identified barriers to the use of BSE and found that younger women cited factors such as being too busy as their reason for not utilizing this screening tool ${ }^{16}$. Therefore, young women are not accessing or using breast cancer information.

Age is a significant predisposing factor of breast cancer which is un-modifiable factor. Age plays a significant role in breast cancer mortality and morbidity. This is because there is decrease in the average age of women diagnose with breast cancer and increase in the life time risk of breast cancer among women ${ }^{17}, 18$. Women living in United State of America have a 12.3\% lifetime risk of being diagnosed with breast cancer. This is more than the lifetime risk of 1990 which was only $9.1 \%^{3}$. This may be as a result of increase in life expectancy, reproductive changes, use of menopausal hormones and obesity ${ }^{3,17}$. 
According to American Cancer Society, $79 \%$ and $88 \%$ of new cancer cases and deaths respectively occurred in women 50 years of age or older ${ }^{3}$. This shows the significant role played by age in breast cancer morbidity and mortality. Women who are older than 40 years of age are encouraged to engage in regular BSE practice which aid early diagnosis of breast cancer. A study conducted in Sokoto, Nigeria shows that majority of the women diagnosed with breast cancer are within the ages of 41-50 years ${ }^{19}$. This show that age remains an important factor in the diagnosis, treatment and prevention of breast cancer. There is need for older women to have more knowledge of breast cancer than the younger ones, though BSE is the only recommended procedure for women younger than 40 years.

There are variations in the findings on the relationship between age and Breast Self-Examination. Some studies reported a significant positive relationship between age and Breast Self-Examination's knowledge and practice among women. Findings of Bilge and Keski ${ }^{11}$ revealed that there is a positive significant relationship between the age of the respondents and the knowledge of BSE. Twenty six percent of women with good knowledge of BSE are over the age of 40 years. This may be because women who are 40 years and above have more experience and may be aware of their increasing chance of getting breast cancer. Though, the study did not assess the women's knowledge of BSE well, because the study asked only two questions: the time for the commencement of BSE and frequency of practice of BSE.

Moreover, findings of Alwan et al. show a significant relationship between age and the knowledge of BSE among women in Iraq ${ }^{20}$. This is similar to the findings of Al-Azmy et al., Alharbi et al., and Onwere et al., that a significant difference exists between the knowledge of BSE and the age of the respondents ${ }^{21,16,22}$. This means that women who are older have more satisfactory knowledge of BSE than those who are younger. Though the findings of Dahlui et al., showed that a significant relationship exist between the knowledge of BSE and age of the respondents. But women who are below 50 years of age have more satisfactory knowledge of BSE than those above 50 years ${ }^{23}$.

Age also influences the practice of BSE among women because of the risk associated with breast cancer. Studies conducted shows that a significant relationship exists between the age of the respondents and the practice of BSE. Women who are older are more likely to practice BSE than those who are younger. Though Breast Self-Examination is the only screening method for younger women ${ }^{21,16,20,11}$. Women that practiced BSE are older than those who did not practice BSE. While, other studies indicate no significant relationship exist between the age of the respondents and the knowledge and practice of BSE $24,25,26,27$.

There are no studies conducted in Sokoto to explore the relationship between the age and Breast SelfExamination among women. Therefore, there is need to discover this relationship in Sokoto, Nigeria. The aim of this study is to examine the relationship between age and knowledge and practice of Breast Self-Examination among women in Sokoto, Nigeria.

\section{Methods}

This study used quantitative approach with cross sectional design to examine the relationship between age and Breast Self-Examination's knowledge and practice among women in Sokoto, Nigeria. Women who were 18 years and above, who attended at least primary school and can read and write simple English, and women who lived in Sokoto for at least six months were recruited in the study. While women who had suffered breast cancer or had undergone mastectomy and women who were non-Nigerians or women who were Nigerians but were on a visit to Sokoto were excluded.

Four hundred women were recruited for the study using multistage sampling technique based on power analysis with Raosoft ${ }^{\mathbb{B}}$ software. The data was collected using questionnaire as an instrument for data collection. The questionnaire consists of demographics, knowledge of BSE and practice of BSE sections. The responses on knowledge sections were rated as follows: 2 marks for correct answers and 0 for incorrect answer or 'I don't know". Scores of 0-19, 20-29 and 30-40 signifies inadequate knowledge, average knowledge and good knowledge respectively. The study received ethical approval from Noguchi Memorial Institute for Medical Research (NMIMR), University of Ghana, Accra. The data was analysed using Statistical Package for Social Sciences (SPSS version 20.0) for descriptive and inferential statistics. All tests were conducted with $95 \%$ confidence level and 0.05 significant levels.

\section{Result}

Four hundred questionnaires were distributed to the respondents, 395 were retrieved but 3 were incompletely filled and therefore only 392 were analysed representing 98.0 response rate.

\section{Practice of Breast Self-Examination}

Table 1 indicates the respondents' practice of Breast Self-Examination. Approximately sixty five percent (65.3\%) of the respondents practiced BSE while 34.7\% did not practice BSE. Meanwhile, among $65.3 \%$ of the respondents that practiced BSE, only $52.7 \%$ practiced BSE monthly which represented only $34.4 \%$ of the 
total respondents. The percentage of the respondents that did not practice BSE gave reasons for not performing BSE as follows: that they did not know how to perform BSE, never heard information about BSE, they did not have time to perform BSE and finally they thought it was unnecessary to do BSE as indicated in table 1

\section{Relationship between the Knowledge of BSE and the Age of the Respondents}

Studies have shown that the prevalence of breast cancer increases with increase in the age of women, therefore, it is necessary to find out if there is any relationship between the age of the respondents and the knowledge of BSE. Table 2 shows a cross tabulation on the relationship between the respondents' knowledge of BSE and the age of the respondents. In the age level, majority (57.7\%) were within 18 - 30 years while only $11.2 \%$ were above 40years. In terms of BSE knowledge level, majority (45.4\%) of the respondents had average knowledge of BSE, while only $25.0 \%$ had in-adequate knowledge of BSE. Moreover, the results of the knowledge level showed that among the $25 \%$ of the respondents with in-adequate knowledge, $71.4 \%$ of them were between $18-30$ years and only $4.1 \%$ were above 40 years. Among the $45.4 \%$ of the respondents with average knowledge, $59.6 \%$ were within $18-30$ years and only $14.6 \%$ were above 40 years of age. However, among the respondents with good knowledge level of BSE, majority (44.8\%) of the respondents were between $31-40$ years while the least is above the age of 40 years with only $12.1 \%$.

Meanwhile, analysis of the age level in relation to knowledge level of BSE showed that among the $57.7 \%$ that were within $18-30$ years, majority $(46.9 \%)$ had average level of knowledge of BSE and only $22.1 \%$ had good knowledge of BSE. More than forty two percent $(42.6 \%)$ of the respondents within $31-40$ years had good knowledge of BSE and only $19.7 \%$ had in-adequate knowledge of BSE. However among the respondents that were above the age of 40 years, $59.1 \%$ had average knowledge as compared with $31.8 \%$ and $9.1 \%$ who had good and in-adequate knowledge of BSE respectively.

A statistical test analysis conducted using Chi-Square showed that there is a significant relationship between the age of the respondents and the knowledge of Breast Self-Examination $\left(\mathrm{X}^{2}=23.919, \mathrm{df}=4, \mathrm{P}=\right.$ 0.000 ). Moreover, there is a significant positive weak relationship between age of the respondents and the knowledge of BSE with contingency coefficient of 0.240 .

\section{Relationship between Age of the Respondents and the Practice of Breast Self-Examination}

Breast cancer is common among old women; therefore it is necessary to examine if there is a relationship between the age of the respondents and the practice of BSE among women in Sokoto. Table 3 present a cross tabulation that examined the relationship between respondents' age and the frequency of practice of BSE. Approximately, fifty three percent (52.7\%) of the respondents that practiced BSE practiced it regularly while $47.3 \%$ did not practice BSE regularly. Among the $52.7 \%$ that practiced BSE regularly, $57.8 \%$ were within $18-30$ years of age group and only $13.3 \%$ were above 40 years of age. Moreover, among the respondents that did not practice BSE regularly (47.3\%), majority $(58.7 \%$ ) were within $18-30$ years of age and $5.0 \%$ were above 40 years of age. However, among the $58.2 \%$ of the respondents within $18-30$ years, $52.3 \%$ practiced BSE regularly and $47.7 \%$ did not practice BSE regularly. Among the respondents within $31-40$ years of age, majority $(53.0 \%)$ did not practiced BSE regularly and $47.0 \%$ practiced BSE regularly. While among the respondents above 40 years of age, majority (75.0\%) practiced BSE regularly and only $25.0 \%$ did not practice BSE regularly.

A statistical test conducted using Chi-Square established a significant relationship between the respondents age group and the frequency of practice of Breast Self-Examination $\left(X^{2}=5.882, \mathrm{df}=2, \mathrm{P}=0.027\right)$. A contingency coefficient further showed that a significant positive weak relationship exist between the practice of BSE and the age of the respondents (Contingency Coefficient of 0.252).

\section{Practice of Breast Self-Examination}

\section{Discussion}

The practice of Breast Self-Examination gives a woman the ability to become breast aware and the opportunity to detect any changes in her breast and report to the hospital early which may influence the treatment decision and the prognosis of breast cancer. The practice of Breast Self-Examination reflects the practical application of the knowledge of Breast Self-Examination. Findings of this study indicate that more than sixty five percent of the respondents practiced BSE but only about thirty four percent practiced BSE regularly. This finding is consistent with the findings of Bilge and Keskin ${ }^{11}$ in Turkey, Burangruangrote et al., ${ }^{28}$ in Thailand, and Dahlui et al., ${ }^{23}$ in Malaysia. According to these authors, majority of women practiced BSE but only few practice BSE regularly. Similarly, in Nigeria the practice of BSE was high among health professionals in Ondo State ${ }^{29}$.

This present study found that women who did not practice BSE reported reasons for their non-practice as lack of knowledge and information on how to do the procedure, lack of time, and BSE being an embarrassing procedure. Others thought that it was wrong to touch their breast and unnecessary to do BSE. These reasons are 
similar to the findings of Alharbi et al. ${ }^{16}$ in which female teachers reported lack of knowledge, dislike to touch their breast, fear of finding a lump and forgetfulness as the reasons for non-performance of BSE. These reasons suggest that there is the need for health workers to intensify their efforts toward providing women with the information on breast cancer and Breast Self-Examination in order to increase the regular practice of BSE and to correct their misconceptions about breast cancer and BSE.

\section{Relationship between age and knowledge of Breast Self-Examination}

Age is a significant risk factor in the incidence of breast cancer. Women who are older are more likely to have breast cancer than the younger ones. Thus, this makes the older women to become more aware about the disease. According to American Cancer Society ${ }^{3}, 79 \%$ and $88 \%$ of new cancer cases and deaths respectively occurred in women who are 50 years of age or older. This study found that there is a significant positive relationship between the knowledge of Breast Self-Examination and the age of the respondents. This means that women who are forty (40) years and above are more likely to have good knowledge of BSE than women who are below 40 years of age. Also, as the age of the respondents' increases there is a likelihood that the knowledge of BSE may also increase. As reported in previous studies older women (40 years and above) are more likely to have adequate knowledge of BSE as compared to younger women ${ }^{11,16,23}$.

\section{Relationship between age and the practice of BSE}

Age plays a significant role in breast cancer morbidity and mortality among women. This is because there is a decrease in the average age of the women diagnosed with breast cancer and there is increase in the life time risk of breast cancer among women ${ }^{3}$. Women who are older than 40 years of age are encouraged to engage in regular Breast Self-Examination which aids early diagnosis of breast cancer ${ }^{30}$. The findings of this study show that a significant positive relationship exists between the practice of BSE and the age of the respondents. This means that women who are 40 years of age and above practiced BSE regularly than those who are younger than 40 years. Therefore, women who are older than 40 years of age are more likely to practice BSE than those who are younger. This finding concurs with the findings of Al-Azmy et al. ${ }^{21}$, in Kuwait, Alwan et al. ${ }^{20}$, in Iraq and Onwere et al..$^{22}$, among women in the eastern part of Nigeria, who reported that women who practiced BSE were older than women who did not practice BSE. This may be due to the amount of information and knowledge that women in Sokoto have on breast cancer and Breast Self-Examination. Elderly women may be aware that age is a significant factor of breast cancer and may perceive the role of BSE in the early diagnosis of breast cancer as relevant.

\section{Conclusion}

Findings of this study show that women's age has significant relationship with their knowledge and practice of BSE. Therefore, there is need for healthcare providers to intensify their effort toward providing BSE information and education to women of all ages. The study was conducted in the urban setting where healthcare services and information are easily accessible, there is need to explore rural women's knowledge and practice of BSE in Nigeria.

\section{Reference}

[1]. Okobia, M., Bunker, C. H. Okonofua, F. E., \& Osime, U., Knowledge, attitude and practice of Nigerian women towards breast cancer: A cross-sectional study. World Journal of Surgical Oncology, 4: 2006, 4-11.

[2]. American Cancer Society, Breast cancer: early detection. (Atlanta, GA, American Cancer Society Inc. 2011)

[3]. American Cancer Society, Breast Cancer Facts and Figures 2013 - 2014. (Atlanta, GA: American Cancer Society Inc. 2013)

[4]. Mason, T. E., \& White, K. M., The role of behavioural, normative and control beliefs in breast self-examination. Women's Health, 47, 2008, 39-56.

[5]. Crossing, S., \& Manaszewicz, R., Breast Self-Examination: Be alert but not alarmed? Medical Journal of Australia, 178 (12), 2003 , 646-647.

[6]. Petro-Nustas, W. \& Mikhail B. I., Factors associated with breast self-examination among Jordanian women. Public Health Nurs;19: 2002, 263-71.

[7]. Carney, P. A., Miglioretti, D. L., Yankaskas, B. C., Kerlikowske, K., Rosenberg, R., Rutter, C. M., ... \& Ballard-Barbash, R., Individual and combined effects of age, breast density, and hormone replacement therapy use on the accuracy of screening mammography. Annals of internal medicine, 138(3), 2003, 168-175.

[8]. Rosenberg, R., \& Levy-Schwartz, R., Breast cancer in women younger than 40 years. International Journal of Fertility and Womens Medicine, 48(5), 2003, 200-205.

[9]. Oztuek, M. Engin, V. S. \& Kisioglu, A. N., The practice of breast self-examination among women at Gulistem district of Isparta. Eastern Journal of Medicine, 4(2), 2010, 47-50.

[10]. Ku, Y., Chinese Cultural Beliefs about Breast Cancer and Breast Self-Examination. Taiwan Journal of Hospice Palliative Care, 9 (4), 2004, 313-335.

[11]. Bilge, U. \& Keskin, A., Breast cancer screening knowledge in a Turkish population: Education is necessary. Procedia-Social and Behavioural Sciences, 116, 2014, 1861-1863.

[12]. Johnson, N., \& Dickson-Swift, V., It usually happens in older women: Young women's perception about breast cancer. Health Education Journal, 67 (4), 2008, 243-257. 
[13]. Thomas, B., Stamler, L. L., Lafreniere, K. D., Ray, R. M., Gao, D. L., Kolesar, J.

k., ... \& James, B. K., Using the internet to identify womens' sources of breast health education and screening. Women \& Health, 36, 2002, 33-48.

[14]. Thornton, H., \& Pillarisetti, R. R., Breast awareness and breast self-examination are not the same. What do these terms mean? Why are they confused? What can we do? European Journal of cancer, 44, 2008, 2118-2121.

[15]. Vahabi, M., Knowledge of breast cancer and screening practices. Health Education Journal, 64(3), 2005, $218-228$.

[16]. Alharbi, N. A., Al-Shammari, M. S., Almutari, B. M., Makbul, G. \& El-Shazly, M. K., Knowledge awareness and practices concerning breast cancer among Kuwait Female Teachers. Alexandria Journal of Medicine, 48: 2012, 75-82.

[17]. Jemal, A., Bray, F., Forman, D., O’Brien, M., Ferlay, J., Center, M. \& Parkin, D. M., Cancer Burden in Africa and Opportunities for Prevention. Cancer, 118, 2012, 4372-84

[18]. Mohamed, N. A. El-Magrabi, N. M. \& Ahmed, S. S., Evaluation of Breast Cancer Knowledge and Breast Self- Examination Practices among Adolescent Blind Girl's in Qena Governorate. Life Sci J; 10 (2), 2013, 1143-1156.

[19]. Agbo, P. S., Khalid, A., \& Oboirien, M. Clinical Presentation, Prevalence and Management of Breast Cancer in Sokoto, Nigeria. J Women's Health Care 3:149, 2014, doi:10.4172/2167-0420.1000149

[20]. Alwan, N. A., Al-Diwan, J. K., Al-Attar, W. M., \& Eliessa, R. A., Knowledge, attitude \& practice towards breast cancer \& breast self-examination in Kirkuk University, Iraq. Asian Pacific Journal of Reproduction, 1(4), 2012, 308-311.

[21]. Al-Azmy, S. F., Alkhabbaz, A., Almutawa, H. A., Ismaiel, A. E., Makboul, G., \& El-Shazly, M. K., Practicing breast selfexamination among women attending primary health care in Kuwait. Alexandria Journal of Medicine 43, 2013, $281-286$.

[22]. Onwere, S. Okoro, O. Chigbu, B. Aluka, C. Kamanu, C. \& Onwere, A. Breast Self-Examination as a method of early detection of Breast Cancer: knowledge and practice among ANC attendees in South-Eastern Nigeria. Pak J Med Sci, 25(1), 2009, $122-125$.

[23]. Dahlui, M., Nig, C.W., Al-Sadat, N., Ismail, S. \& Bulgiba, A.M., Is Breast Self-Examination (BSE) Still Relevant? A Study on BSE Performance among Female Staff of University of Malaya. Asian Pacific J Cancer Prev, 12, 2011, 369-372.

[24]. Amasha, H. A., Breast Self-Examination and risk factors: Awareness of Jordanian Nurses. Health Science Journal, 7(3), 2013, 303314.

[25]. Ghodis, Z. \& Hojjatoleslami, S., A Survey about educational needs of Breast Cancer and BSE in Iranian Women. Procedia-Social and Behavioural Sciences, 46, 2012, 2561-2565.

[26]. Olowokere, A. E., Onibokun, A. C. \& Oluwatosin, A. O., Breast cancer knowledge and screening practices among women in selected rural communities of Nigeria. Journal of Public Health and Epi, 4(9), 2012, 238-245.

[27]. Registe, M. F. \& Porterfield, S. P., Health Beliefs of African American women on BSE. American College of Nurse practitioners, 8 (6), 2012, 446-451.

[28]. Buranaruangrote, S., Sindhu, S., Mayer, D. K., Ratinthorn, A., \& Khuhaprema, T., Factors influencing the stages of breast cancer at the time of diagnosis in Thai women. collegian,21, 2014, 11-20.

[29]. Oluwole, O. C., Awareness, Knowledge and Practice of Breast-Self Examination amongst Female Health Workers in a Nigerian Community. Sudan JMS, 3(2), 2008, 99-104.

[30]. Wilke, L. G., Broadwater, G., Rabiner, S., Owens, E., Yoon, S., Ghate, S., ... \& Seewaldt, V. Breast Self-Examination: Defining a cohort still in need. The American Journal of Surgery 198, 2009, 575-579

Tables

Table 1: Practice of Breast Self - Examination

\begin{tabular}{llll}
\hline Variable & & Frequency & percentage \\
\hline Respondents practice of BSE & Yes & 256 & $\mathbf{6 5 . 3}$ \\
& No & 136 & 34.7 \\
Respondents' frequency of practice of BSE & Total & 392 & 100 \\
& Monthly & 135 & $\mathbf{5 2 . 7}$ \\
& Quarterly & 18 & 7.0 \\
& Bi-annually & 8 & 3.1 \\
& Annually & 22 & 8.7 \\
Respondents' reasons for not & Once in a while & 73 & 28.7 \\
practicing BSE & Total & 100 \\
& Never heard of BSE & 30 & 22.1 \\
& Embarrassing to do & 12 & 8.9 \\
& Don't know how to do & 34 & $\mathbf{2 5 . 0}$ \\
& Do not have time & 30 & 22.1 \\
& Wrong to touch breast & 10 & 7.3 \\
& Unnecessary to do & 20 & 16.6 \\
\hline
\end{tabular}

Table 2: Cross tabulation of Age of the respondents and the knowledge of BSE

\begin{tabular}{|c|c|c|c|c|c|c|c|c|}
\hline \multicolumn{9}{|l|}{ Age of the respondent } \\
\hline \multirow[b]{2}{*}{ Respondents' knowledge } & \multicolumn{2}{|c|}{$18-30$} & \multicolumn{2}{|c|}{$31-40$} & \multirow{2}{*}{\multicolumn{2}{|c|}{$\begin{array}{l}41-60 \\
\text { Freq } \%\end{array}$}} & \multirow{2}{*}{$\begin{array}{l}\text { Total } \\
\text { Freq }\end{array}$} & \\
\hline & Freq & $\%$ & Freq & $\%$ & & & & $\%$ \\
\hline In-adequate knowledge & 70 & 17.9 & 24 & 6.1 & 4 & 1.0 & 98 & 25.0 \\
\hline Average knowledge & 106 & 27.0 & 46 & 11.7 & 26 & 6.6 & 178 & 45.4 \\
\hline Good knowledge & 50 & 12.7 & 52 & 13.3 & 14 & 3.6 & 116 & 29.6 \\
\hline Total & 226 & 57.7 & 122 & 31.1 & 44 & 11.2 & 392 & 100 \\
\hline
\end{tabular}


Table 3: cross tabulation of age of the respondents and the practice of BSE

Respondents practice of Breast Self-Examination

Age of the respondents Regular practice

\begin{tabular}{llllll} 
Freq & $\%$ & Freq & $\%$ & Freq & $\%$ \\
\hline 78 & 30.5 & 71 & 27.7 & 149 & 58.2 \\
39 & 15.2 & 44 & 17.2 & 83 & 32.4 \\
18 & 7.0 & 6 & 2.3 & 24 & 9.4 \\
135 & 52.7 & 121 & 47.3 & 256 & 100
\end{tabular}

$18-30$ years

$31-40$ years

$41-60$ years 